\title{
Impact of Gastro-oesophageal Reflux Disease on Work Productivity Despite Therapy with Proton Pump Inhibitors IN GERMANY
}

\author{
M. Gross ${ }^{1}$, U. Beckenbauer ${ }^{2}$, J. Burkowitz ${ }^{3}$, H. Walther ${ }^{2}$, B. Brueggenjuergen ${ }^{3}$ \\ ${ }^{1}$ Internistische Klinik Dr Müller, München, Germany, \\ ${ }^{2} \mathrm{H}-\mathrm{M}-\mathrm{O}$ Health Management Online AG, Oberhaching, Germany, \\ ${ }^{3}$ Alpha Care GmbH, Celle, Germany
}

\begin{abstract}
Background: Gastro-oesophageal reflux disease (GERD) is a common disorder with consequences for the patient's health-related quality of life (HRQoL). In Germany, few data are available on the impact of GERD on work-related productivity.

Aim: To study the impact of GERD on work productivity despite proton pump inhibitor (PPI) therapy and the association between productivity and symptom duration, severity, and HRQoL.

Methods: Retrospective data from randomly selected patients with chronic GERD symptoms, treated by office-based general practitioners or general internists with routine clinical care, were analyzed together with information from self-administered instruments assessing work productivity (WPAI-GERD), symptoms (RDQ), and HRQoL (QOLRAD).

Results: Reduced productivity was reported by 152 of 249 patients $(61.0 \%)$, although $89.5 \%$ of them were treated with PPI. The reduction in work productivity was $18.5 \%$ in all patients and $30.3 \%$ in those with reduced productivity. Patients with impaired productivity showed a significantly lower HRQoL and more-severe symptoms of reflux disease. In all patients, the mean sick leave attributable to reflux symptoms was 0.6 hours in the previous seven days and 1.4 work days in the previous three months.

Conclusion: GERD has a substantial impact on work productivity in Germany, even in patients receiving routine clinical care and PPI therapy.
\end{abstract}

Key words: Gastro-oesophageal reflux; Sick leave; Medical economics; Proton Pump Inhibitors

\section{INTRODUCTION}

Gastro-oesophageal reflux disease (GERD) is a common and costly chronic disorder, with consequences for the patient's health-related quality of life (HRQoL) [1-3]. The prevalence of GERD has been estimated to be between $10 \%$ and $20 \%$ in the Western world [1]. In Germany, $14 \%$ of the adult population report moderate reflux symptoms and $4 \%$ report severe symptoms [4]. Besides esophageal symptoms, patients suffer from chest pain and a variety of extra-esophageal symptoms, including asthma, chronic cough, and laryngitis [5]. Esophageal and extra-esophageal symptoms are regarded as the reasons for the experience of pain, lack of vitality, and feelings of poor physical and mental health [6]. GERD substantially impairs all aspects of HRQoL $[6,7]$.

The wide-ranging effects of GERD on health and well-being can have consequences for the performance of the affected individuals, particularly at work [8]. In several studies that have analyzed measures of work productivity, the loss of productivity ranged from $6 \%$ to $42 \%$ among individuals with GERD [8]. GERD causes significant indirect costs attributable to reduced productivity and time off work [9]. A German study showed that $10 \%$ of total disease-related costs were indirect costs arising from working days lost to illness [2]. One analysis estimated a loss of gross domestic product of $€ 688$ million/year due to GERD-related inability to work in Germany [10].

In Germany, the impact of GERD not only on the ability to work [10] but also on overall work-related productivity has been studied only once within an international context [11]. The overall loss in productivity was 3.5 hours/week [11]. However, the results were difficult to compare because a non-standardized instrument was used.

The aim of this study was to explore the extent of GERD-induced loss of work productivity (working days lost and reduced productivity while working) in a German primary-care patient population with chronic reflux symptoms. The association between productivity loss from GERD symptoms and health-related quality of life (HRQoL) was also analyzed.

\section{MAterials AND METHODS}

\section{STUDy SubJECTS}

In Germany, the initial management of GERD occurs in primary care, provided by office-based physicians. This includes a clinical evaluation, further diagnostic procedures, and medical treatment [12]. Therefore, patients with chronic reflux symptoms were randomly selected from a sample of primary-care patients of office-based physicians (general practitioners [GPs] and 
general internists) in the Munich area (both rural and urban districts) in southern Germany. All physicians cooperated with the "Health Management Online" organization (H-M-O AG) in Oberhaching, southern Germany, which selected the participating physicians. Seventeen of the 78 physicians which were invited to participate took part in the study including 13 GPs and 4 general internists. Data for this retrospective, multicenter observational study were collected between July and November, 2007.

The inclusion criteria were: (1) at least 18 years old; (2) at least one visit because of reflux symptoms more than six months before study entry and a follow-up visit for reflux symptoms between six and three months before study entry. These criteria were chosen to include only patients with chronic reflux disease. GERD was diagnosed by the physicians according to the International Classification of Diseases, Tenth Revision (ICD 10), German Modification 2007, according to the codes given in Table 1. An upper endoscopy recently or a longer time ago was not mandatory. The exclusion criteria included other significant upper gastrointestinal disorders (including Zollinger-Ellison syndrome, gastric or duodenal ulcer, esophageal stricture, and a history of dysplasia in Barrett's esophagus).

The physicians identified all patients in their office database who fulfilled the inclusion criteria. An anonymized list of patients was transferred to the study organization which randomly selected the patients. The patients were invited in writing to participate in the study and to make an appointment with their physician. Written informed consent was obtained from all patients before study entry. The patients completed the questionnaires in the office of their physician.

Table 1. ICD 10 GERD diagnostic codes identifying Patients with reflux disease.

\begin{tabular}{ll}
\hline Code & Diagnosis \\
\hline K21 & Gastroesophageal reflux disease \\
K21.0 & $\begin{array}{l}\text { Gastroesophageal reflux disease with esophagitis - } \\
\text { Reflux esophagitis }\end{array}$ \\
K21.9 & Gastroesophageal reflux disease without esophagitis \\
R12 & Heartburn - Excludes dyspepsia
\end{tabular}

\section{INSTRUMENTS}

Data concerning resource use and treatment within the observation period over the preceding six months was gathered retrospectively from patient records. To measure the treatment outcomes and the patients' GERD-related distress, a questionnaire was completed by the participants, which included standardized validated self-administered instruments to assess work productivity and evaluate both symptoms and HRQoL in assessing the response to treatment.

Quality of Life with Reflux and Dyspepsia (QOLRAD) The QOLRAD was developed to assess HRQoL in patients suffering from GERD symptoms or dyspep- sia [13]. The questionnaire consists of 25 items, which are organized into five domains (3-6 items each): emotional distress, sleep disturbance, eating and drinking problems, physical/social functioning, and vitality. The degree and frequency of distress and the patients' feelings during the preceding week are assessed on a seven-point Likert scale, with a higher score representing less frequency or distress. Although there is no detailed evaluation of QOLRAD, a difference of approximately one point is considered to be clinically relevant [14]. A German translation of QOLRAD has shown good psychometric qualities [15].

\section{Reflux Disease Questionnaire (RDQ)}

The original RDQ is a diagnostic instrument with 12 questions that evaluate the frequency and severity of burning behind the sternum, pain behind the sternun, upper stomach burning, upper stomach pain, acid taste in the mouth, and movement of material during the preceding four weeks [16]. A German version was created to assess the treatment response for a shorter period of one week using six-point scales ranging from no occurrence to daily/severe [17]. This version has been carefully validated and adequate validity, reliability, and sensitivity have been demonstrated. With principle components analysis, three factors (regurgitation, heartburn, and dyspepsia) were identified. A combined score for the factors regarding GERD symptoms (regurgitation + heartburn) could be calculated.

\section{Work Productivity and Activity Impairment Questionnaire (WPAI-GERD)}

The WPAI-GERD is the GERD-specific validated version of a general health measure that has been modified for several health conditions [18]. It was developed to estimate the impact of heartburn and acid regurgitation on productivity and has become a standard tool for the evaluation of work productivity [8, 19]. The questionnaire contains three open-ended questions about hours absent from work for health reasons, hours absent from work for other reasons, and the number of hours worked during the last seven days. The patients were instructed not to include the time spent participating in the study as time absent from work. In two further questions, patients rated the impact of reflux symptoms on their productivity (percentage reduction in productivity at work). Based on the WPAI-GERD results, a work productivity score (WPS) was calculated, which expresses the lost productivity because of GERD symptoms for each patient as a percentage of their total potential productivity. A WPS of zero means no reduced productivity, a value above zero means reduced productivity.

WPS $=[$ hours absent from work + percentage reduced productivity at work $\times$ hours actually worked) /(hours absent from work + hours lost for other reasons + hours actually worked) $\times 100$

\section{Absenteeism from work in the preceding three months}

The patients were asked about their absenteeism from work (hours or days) in the preceding three months resulting from reflux symptoms, with or without a medical certificate. In Germany, most employees 
must present a medical certificate when absent from work, although sometimes only when absent for more than two days.

\section{STATISTICAL ANALYSIS}

To compare differences in the characteristics of the samples, $t$ tests were used for continuous variables and $\chi^{2}$ tests for discrete variables. All analyses were performed with SPSS 15.0 (SPSS Inc., Chicago, IL, USA).

\section{Human Subject Protection}

This study was conducted in accordance with the latest revision of the Declaration of Helsinski. The study protocol was reviewed by the ethics committee of the Bavarian State Chamber of Physicians.

\section{RESULTS}

\section{Patient Characteristics}

A total of 627 patients with chronic GERD symptoms were randomly selected from all the patients fulfilling the inclusion criteria according to primary-care officebased GPs and internists. Two hundred sixty-five $(42.2 \%)$ of them were gainfully employed at the time of the study $(31.4 \%$ full-time employment, $10.9 \%$ part-time employment), $45.0 \%$ were retired, and $7.2 \%$ were unemployed. Two hundred forty-nine (39.7\%) were gainfully employed, completed the WPAIGERD, and were therefore included in the analysis. The proportion of males to females was 109 to 140 , with a mean age of 48.9 years. Of the respondents, $50 \%$ had had symptoms of GERD for at least 3.5 years. Reduced productivity (WPS $>0$ ) was reported by 152 patients $(61.0 \%)$. Patients with reduced productivity had suffered GERD symptoms for a significantly shorter period than had patients whose productivity was not reduced (mean 6.1 vs 9.1 years, respectively). The sex distribution, full-time employment, and GERD diagnosis (ICD 10 codes) were similar in the two groups (Table 2). There were no significant differences in the use of either proton pump inhibitor (PPI) medication $(89 \%)$ or histamine-2-receptor antagonists $(13 \%)$ between patients with and those without reduced productivity. Most patients were treated with omeprazole $(51 \%$ of the patients), followed by esomeprazole $(16 \%)$, pantoprazole $(14 \%)$, lansoprazole $(1 \%)$, and rabeprazole $(1 \%)$.

\section{Work Productivity}

For $6 \%$ of the respondents, their GERD symptoms had been a cause of absenteeism in the preceding seven days. On average, these patients missed 10.4 working hours in that week. The average absence resulting from GERD reported by all 249 patients was $0.63 \mathrm{~h}$ in that week (2.4\% of work time).

The WPS is composed of absenteeism and reduced productivity while working attributable to GERD symptoms, and refers to the total working time. In all patients, WPS was 18.5 which means an average productivity loss because of GERD symptoms of $18.5 \%$ (Table 3). In patients with reduced productivity, WPS was 30.3

Table 2. Study group characteristics

\begin{tabular}{|c|c|c|c|c|}
\hline Characteristic & $\begin{array}{l}\text { Working } \\
\text { patients } \\
\text { total } \\
\mathrm{N}=249\end{array}$ & $\begin{array}{c}\text { No reduced } \\
\text { productivity } \\
\text { (WPS) } \\
\mathrm{N}=97\end{array}$ & $\begin{array}{c}\text { Reduced } \\
\text { productivity } \\
\text { (WPS) } \\
\mathrm{N}=152\end{array}$ & $P$ value \\
\hline Mean age $[$ years $( \pm S D)]$ & $48.9(11.5)$ & $49.9(11.7)$ & $48.2(11.3)$ & 0.75 \\
\hline \multicolumn{5}{|l|}{$\operatorname{Sex}[\mathrm{n}(\%)]$} \\
\hline Male & $109(43.8)$ & $46(47.4)$ & $63(41.4)$ & \multirow[t]{2}{*}{0.36} \\
\hline Female & $140(56.2)$ & $51(52.6)$ & $89(58.6)$ & \\
\hline \multicolumn{5}{|l|}{ Employment $[\mathrm{n}(\%)]$} \\
\hline Full time & $166(66,7)$ & $54(55.7)$ & $112(73.7)$ & 0.29 \\
\hline \multicolumn{5}{|l|}{ Symptom duration } \\
\hline Mean [years (SD)] & $7.3(8.8)$ & $9.1(9.7)$ & $6.1(7.9)$ & 0.01 \\
\hline Median [years (inner quartile range $]$ & $3.5(7.9)$ & $5.6(10.1)$ & $2.8(6.2)$ & $\mathrm{n} / \mathrm{a}$ \\
\hline \multicolumn{5}{|l|}{ Diagnosis (ICD 10) [n (\%)]* } \\
\hline K21 & $58(23.3)$ & $20(20.6)$ & $38(25.0)$ & 0.45 \\
\hline K21.0 & $101(40.6)$ & $43(44.3)$ & $58(38.2)$ & 0.36 \\
\hline K21.9 & $66(26.5)$ & $24(24.7)$ & $42(27.6)$ & 0.66 \\
\hline $\mathrm{R} 12$ & $72(28.9)$ & $29(29.9)$ & $43(28.3)$ & 0.89 \\
\hline \multicolumn{5}{|l|}{ Proton pump inhibitor use $[\mathrm{n}(\%)]$} \\
\hline Yes & $222(89.1)$ & $86(88.7)$ & $136(89.5)$ & 0.83 \\
\hline \multicolumn{5}{|l|}{ Histamine-receptor-2 use use [n (\%)] } \\
\hline Yes & $33(13.3)$ & $10(10.3)$ & $23(15.1)$ & 0.27 \\
\hline
\end{tabular}

*Multiple diagnoses possible 
Table 3. Work productivity score (WPAI-GERD) for the last seven days in all patients and in patients with normal or reduced productivity [mean $(\mathrm{SD})]$.

\begin{tabular}{|c|c|c|c|c|}
\hline $\begin{array}{l}\text { Component } \\
\text { (time frame: last seven days) }\end{array}$ & $\begin{array}{l}\text { Working } \\
\text { patients } \\
\text { total } \\
\mathrm{N}=249\end{array}$ & $\begin{array}{l}\text { No reduced } \\
\text { productivity } \\
\text { (WPS) } \\
\text { N }=97\end{array}$ & $\begin{array}{c}\text { Reduced } \\
\text { productivity } \\
\text { (WPS) } \\
\mathrm{N}=152\end{array}$ & $P$ value \\
\hline Hours absent from work because of reflux symptoms & $0.63(3.75)$ & 0.0 & $0.65(3.29)$ & $\mathrm{n} / \mathrm{a}$ \\
\hline Percentage reduced productivity at work & $17.6(21.3)$ & 0.0 & $28.9(20.4)$ & $\mathrm{n} / \mathrm{a}$ \\
\hline Work productivity score (WPS) & $18.5(22.5)$ & 0.0 & $30.3(21.8)$ & $\mathrm{n} / \mathrm{a}$ \\
\hline
\end{tabular}

Table 4. Working days lost due to GERD during the preceding three months.

\begin{tabular}{llll}
$\begin{array}{l}\text { Type of working days lost } \\
\text { time frame: last three months) }\end{array}$ & $\begin{array}{c}\text { Working } \\
\text { patients } \\
\text { total } \\
\mathrm{N}=249\end{array}$ & $\begin{array}{c}\text { No reduced } \\
\text { productivity } \\
\text { (WPS) } \\
\mathrm{N}=97\end{array}$ & $\begin{array}{c}\text { Reduced } \\
\text { productivity } \\
\text { (WPS) } \\
\mathrm{N}=152\end{array}$ \\
\hline total working days lost & $1.35(4.83)$ & $0.57(2.99)$ & $1.84(5.64)$ \\
working days lost with medical certificate & $0.59(2.79)$ & $0.47(2.64)$ & $0.66(2.88)$ \\
working days lost without medical certificate & $0.76(3.67)$ & $0.09(0.57)$ & $1.18(4.61)$ \\
\hline
\end{tabular}

Beyond the WPAI-GERD, we asked the patients how many working days had been lost during the preceding three months. In Germany, many employees only require a medical certificate from a physician confirming their illness for an absence of more than two days. In total, $1.35 \pm 4.83$ working days were lost in the last three months (Table 4). The mean number of lost working days among the $12.1 \%$ of all 249 patients with absence from work was $11.1 \pm 8.89$ days. The overall mean number of working days lost with a medical certificate for GERD was $0.59 \pm 2.78$ days. This kind of lost working days was reported by $7.1 \%$ of patients (mean $8.4 \pm 6.59$ days). Patients also reported an average of $0.76 \pm 3.67$ lost working days without a medical certificate $(7.5 \%$ of patients with a mean loss of $9.63 \pm 9.36$ days).

Patients with reduced productivity during the preceding seven days showed significantly more lost work days in the preceding three months (Table 4). Only the days off without a medical certificate (usually less than three days absence) differed significantly between the two groups, not the days lost during a longer period of inability to work.

\section{HRQOL}

Reduced HRQoL correlated significantly with impaired productivity (Table 5). Patients with reduced productivity showed a significantly lower HRQoL in all dimensions of QOLRAD. The largest mean differences were observed in the dimensions "emotional distress" (0.84 points) and "vitality" (0.83 points). The lowest total scores were reported by patients with reduced productivity in the dimensions "vitality", "sleep disturbance", and "food/drink problems".

\section{SYMPTOM SEVERITY}

Symptom assessment revealed a higher frequency of GERD and worse symptoms during the preceding seven days in patients with reduced work productivity (Table 6). Significant differences were observed on each RDQ symptom scale for these patients. Regurgitation was the most relevant sign, with the highest mean score (1.84) and the greatest difference between employees without reduced productivity and those with reduced productivity $(-0.44)$.

Table 5. Health-related Quality of Life (QOLRAD) in all patients and in patients with normal or reduced productivity.

\begin{tabular}{|c|c|c|c|c|c|}
\hline QOLRAD dimension & $\begin{array}{l}\text { Working } \\
\text { patients } \\
\text { total } \\
\mathrm{N}=249\end{array}$ & $\begin{array}{c}\text { No reduced } \\
\text { productivity } \\
\text { (WPS) } \\
\mathrm{N}=97\end{array}$ & $\begin{array}{c}\text { Reduced } \\
\text { productivity } \\
\text { (WPS) } \\
\mathrm{N}=152\end{array}$ & Difference & $P$ value \\
\hline Emotional distress & $5.34(1.47)$ & $5.85(1.39)$ & $5.01(1.44)$ & 0.84 & $<0.001$ \\
\hline Food/drink problems & $5.17(1.32)$ & $5.52(1.37)$ & $4.95(1.24)$ & 0.58 & $<0.01$ \\
\hline Physical/social functioning & $5.87(106)$ & $6.29(0.99)$ & $5.60(1.01)$ & 0.68 & $<0.001$ \\
\hline Sleep disturbance & $525(1.48)$ & $5.72(1.46)$ & $4.95(1.41)$ & 0.77 & $<0.001$ \\
\hline Vitality & $5.17(1.47)$ & $5.67(1.45)$ & $4.84(1.38)$ & 0.83 & $<0.001$ \\
\hline
\end{tabular}


Table 6. Symptom Score (Reflux Disease Questionnaire RDQ) in all patients and in patients with normal or reduced productivity.

\begin{tabular}{|c|c|c|c|c|c|}
\hline RDQ Scale & $\begin{array}{l}\text { Working } \\
\text { patients } \\
\text { total } \\
\mathrm{N}=249\end{array}$ & $\begin{array}{l}\text { No reduced } \\
\text { productivity } \\
\text { (WPS) } \\
\mathrm{N}=97\end{array}$ & $\begin{array}{c}\text { Reduced } \\
\text { productivity } \\
\text { (WPS) } \\
\mathrm{N}=152\end{array}$ & Difference & $P$ value \\
\hline Regurgitation & $1.67(1.41)$ & $1.40(1.39)$ & $1.84(1.40)$ & -0.44 & 0.02 \\
\hline Heartburn & $1.23(1.36)$ & $1.00(1.29)$ & $1.38(1.39)$ & -0.38 & 0.04 \\
\hline Dyspepsia & $1.48(1.36)$ & $1.21(1.35)$ & $1.64(1.33)$ & -0.43 & 0.01 \\
\hline GERD (regurgitation + heartburn) & $1.45(1.22)$ & $1.20(1.20)$ & $1.61(1.20)$ & -0.41 & $<0.01$ \\
\hline
\end{tabular}

\section{Discussion}

This study evaluated a group of employed patients visiting a GP or primary-care internist for chronic GERD symptoms. The analysis was based on retrospective data and self-administered instruments were used to determine the extent of GERD-caused loss of work productivity and its association with GERD symptoms and HRQoL. To the best of our knowledge, this is the first German study to use the standardized disease-specific WPAI-GERD questionnaire to quantify productivity loss and compare the results with international studies.

Of the patients evaluated, $12.1 \%$ had reported absence from work attributable to GERD symptoms in the preceding three months. This corresponds very well to the $14 \%$ of employed patients reporting days of sick leave in the preceding year in the German ProGERD study [10]. Sixty-one percent of the employed patients reported reduced productivity attributable to GERD while at work in the preceding seven days, resulting in a mean absence from work of 0.63 hours and a reduction of $18.5 \%$ in overall work productivity (WPS 0,185). This absence from work and WPS are lower than those reported in other studies. Among the Swedish working population consulting a GP for current or recent symptoms of heartburn, a mean absence from work of $2.5 \mathrm{~h}$ per week was reported, with a WPS of $23 \%$ [20]. In a study in Spain among patients with nocturnal heartburn, a mean absence from work of $1.4 \mathrm{~h}$ and a WPS of $26 \%$ were reported [21]. These differences in sick leave may indicate that socioethical or socioeconomic factors influence patients' willingness to be absent from work because of reflux symptoms.

When the lost working days are extrapolated to the total number of working days (1.35 of 65 working days in three months), an average of $2.1 \%$ in three months was calculated, only slightly lower than the $2.4 \%$ of lost work time measured with the WPAI-GERD in the preceding seven days. Only one study in Spain used a similar approach and reported absenteeism of the same magnitude [22]. The German ProGERD study reported that 2.5 working days had been lost because of GERD in the year before the patients' inclusion in the study [10]. This difference of 2.5 days/year versus 1.35 days/three months may be the result of recall bias. When patients report their days off work for the preceding year, the data probably underestimate the disease-related absences from work. It has been shown that there is a relevant recall bias even when self-reported absences from work in a four-week recall period are compared with those for a two or one week period [23]. Therefore, our finding of 1.35 lost working days in three months may be an accurate estimate of the days lost to work in Germany.

Respondents with reduced productivity (WPS > 0) had significantly more days off without a medical certificate (indicating short periods of absenteeism, for 1-2 days), whereas longer periods of inability to work (with a medical certificate) did not differ significantly between the two groups.

Clear and consistent associations were found between HRQoL and reduced productivity at work in all dimensions of the QOLRAD. These results confirm those of another German study. The mean scores in the group of patients with reduced productivity were similar to or worse than those of patients with moderate heartburn in the German QOLRAD validation study [15]. There were major differences in HRQoL between patients with and without reduced productivity in the dimensions "vitality" and "emotional distress". This may point to some psychological strain caused by acute GERD symptoms. "Sleep disturbance" and "food/drink problems" were also significantly lower in patients with reduced productivity, corresponding well to the finding that nocturnal symptoms are a significant predictor of reduced work productivity [24].

Symptom severity (RDQ) correlates both with HRQoL and work productivity. Patients with higher ( i.e., worse) results on the RDQ had significant more reduced productivity at work and impaired HRQoL. The RDQ scale "regurgitation" turned out to be the most relevant scale with the largest difference and highest mean score.

Most of the patients in this study (61\%) experienced an inability to work or a loss of productivity, although $89 \%$ of all patients were treated with PPIs. This proportion was higher than the treated patients in other studies, in which only $13 \%-30 \%$ of patients took PPI medications [22, 24, 25]. The use of PPI in this study is similar only to the frequency of PPI-treated patients $(78.4 \%)$ in a recent Australian investigation [26]. This high percentage of patients treated with PPI is most likely due to the inclusion criteria (patients treated with routine clinical care). Obviously, the high rate of patients treated with PPI medication did not effectively prevent absences from work.

The lack of difference in PPI use between the patients with and without reduced productivity should 
be evaluated in more detail. Several explanations are possible. In this retrospective study, patients with more-severe symptoms may have been treated with a higher dose or a more potent PPI than patients who were less affected. Furthermore, most patients may have been on a demand therapy regimen. The number of days on which they received PPI medication may have differed in the two patient groups. However, the sample size in this study was too small to address these questions.

The loss of gross domestic product can be estimated based on the reported days lost to work. The human capital method uses the full replacement costs, independent of whether the worker is replaced or not [27]. Based on the human capital method of calculating the costs of illness, the total loss of gross domestic product is in the order of 4.2 billion euros annually in Germany (1.35 lost working days in three months equals 5.4 lost working days per year, 33 million employees, 0.14 prevalence of moderate reflux symptoms [4], €170/day mean daily gross wage). However, this is probably an over-estimate. In the present study, only patients with chronic reflux symptoms who had presented twice to a physician were included (at least one visit at least six months before enrolment and a second visit 3-6 months before enrolment). This probably represents a group of patient with severe or refractory GERD, resulting in a higher number of sick leave days than in the whole group of GERD patients. There may also be a selection bias towards patients with increased numbers of sick leave days in the preceding six months, attributable to the inclusion criteria. However, if the sick leave days were representative of only one fifth of the $14 \%$ of the population with moderate reflux symptoms, the loss of gross domestic product would still be in the order of 800 million euros annually. This estimate is close to the $€ 668$ million/year calculated in the German ProGERD study [10].

\section{Strengths and Limitations of THE STUdy}

The major strength of our study is that the analysis of productivity loss was made with the most widely used GERD-specific validated questionnaire (WPAI-GERD). To the best of our knowledge, this kind of study has not been performed before in Germany. Thus, the impact of reflux disease on work productivity in a random sample of GERD patients was demonstrated and compared with international results.

The study has several limitations. First, the study is an observational design, which does not allow for the direct comparison of different treatment regimens or for risk-factor assessment. Second, insufficient data were available on co-morbidities. Therefore we could not perform a logistic regression model to analyze whether GERD is an independent predictor of the loss of productivity. However, it can be stated that a high percentage of German patients with chronic reflux disease report a reduced work productivity.

Furthermore, the respondents were recruited by primary-care physicians. It can be assumed that in Germany, the more-severe cases are treated by officebased specialists. The consequences are unclear and range from better treatment with less productivity loss to a greater impact on work productivity because of more-severe symptoms.

The vast majority of patients were treated with omeprazole. For this reason, no comparison of the efficacy of various PPIs on work productivity could be made. Moreover, insufficient data were obtained regarding the prescribed therapy regimens (on demand or daily use of PPIs). The recall period of six months for the prescribed medication was too short and the mean number of consultations with the patients was too low to calculate the average number of tablets taken per day. Therefore, these two therapeutic regimens could not be compared in this study.

\section{CONClusions}

GERD has a substantial effect on employees' productivity in Germany. Obviously, an appreciable productivity loss exists, even among patients in routine clinical care and undergoing treatment with PPI. Symptom severity and impaired HRQoL are significant predictors of reduced work productivity. Further investigations of larger study populations and the inclusion of patients under specialist care would be beneficial in examining the reasons for the suboptimal response to PPI therapy in terms of productivity loss.

Disclosure: The study was supported by an unrestricted research grant from AstraZeneca GmbH, Wedel, Germany.

\section{REFERENCES}

1. Dent J, El-Serag HB, Wallander MA, Johansson S. Epidemiology of gastro-oesophageal reflux disease: a systematic review. Gut 2005 May; 54(5): 710-7.

2. Willich SN, Nocon M, Kulig M, Jaspersen D, Labenz J, Meyer-Sabellek W, Stolte M, Lind T, Malfertheiner P. Cost-of-disease analysis in patients with gastro-oesophageal reflux disease and Barrett's mucosa. Aliment Pharmacol Ther 2006 Feb 1;23(3):371-6.

3. Kulig M, Leodolter A, Vieth M, Schulte E, Jaspersen D, Labenz J, Lind T, Meyer-Sabellek W, Malfertheiner P, Stolte M, Willich SN. Quality of life in relation to symptoms in patients with gastro-oesophageal reflux diseasean analysis based on the ProGERD initiative. Aliment Pharmacol Ther 2003; Oct 15;18(8):767-76.

4. Nocon M, Keil T, Willich SN. Prevalence and sociodemographics of reflux symptoms in Germany-results from a national survey. Aliment Pharmacol Ther 2006 Jun 1;23(11): 1601-5.

5. Hungin AP, Raghunath AS, Wiklund I. Beyond heartburn: a systematic review of the extra-oesophageal spectrum of reflux-induced disease. Fam Pract. 2005 Dec; 22(6):591-603.

6. Wiklund I. Review of the quality of life and burden of illness in gastroesophageal reflux disease. Dig Dis 2004; 22(2): 108-14.

7. Ronkainen J, Aro P, Storskrubb T, Lind T, BollingSternevald E, Junghard O, Talley NJ, Agreus L. Gastrooesophageal reflux symptoms and health-related quality of life in the adult general population - the Kalixanda study. Aliment Pharmacol Ther 2006 Jun 15;23(12):172533.

8. Wahlqvist P, Reilly MC, Barkun A. Systematic review: the impact of gastro-oesophageal reflux disease on work productivity. Aliment Pharmacol Ther 2006 Jul 15; 24(2): 259-72. 
9. Wahlqvist P, Brook RA, Campbell SM, Wallander MA, Alexander AM, Smeeding JE, Kleinman NL. Objective measurement of work absence and on-the-job productivity: a case-control study of US employees with and without gastroesophageal reflux disease. J Occup Environ Med 2008 Jan;50(1):25-31.

10. Leodolter A, Nocon M, Kulig M, Willich SN, Malfertheiner P, Labenz J. Gastro esophageal reflux disease is associated with absence from work: Results from a prospective cohort study. World J Gastroenterol 2005 Dec 7;11(45):7148-51.

11. Liker H, Jones R, Ducrotte P. The effect of sleep disturbance due to gastroesophageal reflux diesease on work and leisure productivity: results from a multinational survey. Gastroenterology 2005; 128: A386

12. Meining A, Driesnack U, Classen M, Rösch T. Management of gastroesophageal reflux disease in primary care: results of a survey in 2 areas in Germany. Z Gastroenterol 2002 Jan; 40(1): 15-20.

13. Wiklund IK, Junghard O, Grace E, Talley NJ, Kamm M, Veldhuyzen van Zanten S, Paré P, Chiba N, Leddin DS, Bigard MA, Colin R, Schoenfeld P. Quality of Life in Reflux and Dyspepsia patients. Psychometric documentation of a new disease-specific questionnaire (QOLRAD). Eur J Surg Suppl 1998; 583: 41-9.

14. Crawley J, Frank L, Joshua-Gotlib S, Flynn J, Frank S, Wiklund I. Measuring change in quality of life in response to Helicobacter pylori eradication in peptic ulcer disease: the QOLRAD. Dig Dis Sci 2001 Mar; 46(3): 571-80.

15. Kulich KR, Malfertheiner P, Madisch A, Labenz J, Bayerdörffer E, Miehlke S, Carlsson J, Wiklund IK. Psychometric validation of the German translation of the Gastrointestinal Symptom Rating Scale (GSRS) and Quality of Life in Reflux and Dyspepsia (QOLRAD) questionnaire in patients with reflux disease. Health Qual Life Outcomes 2003 Oct 28; 1: 62.

16. Shaw MJ, Talley NJ, Beebe TJ, Rockwood T, Carlsson R, Adlis S, Fendrick AM, Jones R, Dent J, Bytzer P. Initial validation of a diagnostic questionnaire for gastroesophageal reflux disease. Am J Gastroenterol 2001 Jan; 96(1): 52-7.

17. Nocon M, Kulig M, Leodolter A, Malfertheiner P, Willich SN. Validation of the Reflux Disease Questionnaire for a German population. Eur J Gastroenterol Hepatol 2005 Feb; 17(2): 229-33.

18. Reilly MC, Zbrozek AS, Dukes EM. The validity and reproducibility of a work productivity and activity impairment instrument. Pharmacoeconomics 1993 Nov; 4(5): 353-65.
19. Wahlqvist P, Carlsson J, Stalhammar NO, Wiklund I. Validity of a Work Productivity and Activity Impairment questionnaire for patients with symptoms of gastroesophageal reflux disease (WPAI-GERD)—results from a cross-sectional study. Value Health 2002 Mar-Apr; 5(2):106-13.

20. Wahlqvist P. Symptoms of gastroesophageal reflux disease, perceived productivity, and health-related quality of life. Am J Gastroenterol 2001 Aug; 96(8 Suppl): S57-61.

21. Calleja JL, Bixquert M, Maldonado J. Impact of nocturnal heartburn on quality of life, sleep, and productivity: the SINERGE study. Dig Dis Sci 2007 Oct; 52(10): 2858-65.

22. Rey E, Elola-Olaso C, Rodríguez Artalejo F, Díaz-Rubio M. Impact of gastroesophageal reflux symptoms on health resource usage and work absenteeism in Spain. Rev Esp Enferm Dig 2006 Jul; 98(7): 518-26.

23. Stewart WF, Ricci JA, Leotta C. Health-related lost productive time (LPT): recall interval and bias in LPT estimates. J Occup Environ Med 2004 Jun; 46(6 Suppl): S1222.

24. Dean BB, Crawley JA, Schmitt CM, Wong J, Ofman JJ. The burden of illness of gastro-oesophageal reflux disease: impact on work productivity. Aliment Pharmacol Ther 2003 May 15; 17(10): 1309-17.

25. Jones R, Armstrog D, Mnalfertheiner P, Ducrotté P. Does the treatment of gastroesophageal reflux disease (GERD) meet patients' needs? A survey-based study. Curr Med Res Opin 2006 April; 22(4): 657-62.

26. Kirby CN, Piterman L, Nelson MR, Dent J. Gastro-oesophageal reflux disease--impact of guidelines on GP management. Aust Fam Physician 2008 Jan-Feb; 37(1-2): 73-7.

27. Koopmanschap MA, Rutten FF. A practical guide for calculating indirect costs of disease. Pharmacoeconomics 1996 Nov;10(5):460-6.

Received: August 20, 2009 / Accepted: September 8, 2009

Address for correspondence:

Prof. Dr. Manfred Gross

Internistische Klinik Dr. Müller

Am Isarkanal 36

81379 München

E-mail: gross@muellerklinik.de 